The Art of Living and Positive Psychology in Dialogue

This is the pre-published version of the article. Please use the reference below to cite this article:

Teschers, C. (2015). The Art of living and positive psychology in dialogue. Educational Philosophy and Theory, 47(9), 970-981. DOI:10.1080/00131857.2015.1044839 


\title{
The Art of Living and Positive Psychology in Dialogue
}

\author{
Christoph Teschers \\ College of Education, University of Canterbury, New Zealand \\ christoph@teschers.com
}

\begin{abstract}
The idea of happiness boomed in the public as well as in the academic domain over the last decade and has not reached its peak yet. However, the understanding of happiness (understood as eudaimonia) as being the utmost goal of human beings is hardly new. Philosophers have discussed this topic, under various terms, throughout history. One of the most recent philosophical concepts has been conducted by Wilhelm Schmid in his book Philosophie der Lebenskunst [Philosophy of the Art of Living], which is a theory about the good and beautiful life from a modern perspective under consideration of the philosophical history of this topic. Martin Seligman presented the "happiness formula" in his book Authentic Happiness in 2002 and research about happiness, subjective well-being and lifesatisfaction (among others) began to form the field of positive psychology. This article provides a critical comparative analysis of philosophical concepts of the art of living (with focus on Schmid's concept Lebenskunst) and positive psychological research from an educational point of view. It will explore the extent of common ground between these disciplines, where they differ, and where they might be complementary. It will also highlight aspects which are important for an educational approach to the art of living, the good life and teaching happiness in classrooms, which I consider to be of high importance for the future and development of education, teaching and schooling.
\end{abstract}

\section{Introduction}

The idea of happiness boomed in the public as well as in the academic domain over the last decade and has not reached its peak yet. Martin Seligman presented the "happiness formula" in his book Authentic Happiness in 2002; research about happiness, subjective well-being and life-satisfaction (among others) began to form the field of positive psychology; more then 600,000 books $^{1}$ are available concerning the topic of happiness and/or well-being; organisations and indices have been founded, such as The Happy Planet Index ${ }^{2}$, The World Values Survey ${ }^{3}$ and the World Database of Happiness ${ }^{4}$. Recently, even governments, Britain (Easton, 2006) is one example Bhutan another one, started to shift their focus to include individual happiness, when evaluating the state of the country and the living situation of its people. To support this development, van Suntum \& Uhde (2010) developed a so called "Glücks-BIP" [happiness-GDP], which includes the country's GDP combined with additional indicators for measuring happiness, based on positive psychology research. Even some schools and colleges have taken up the task of improving their pupils" happiness and life skills. Examples are the "well-being centre" at Geelong Grammar School in Australia or happiness classes at the Wellington College in Berkshire, 
UK. Jules Evans (2008) pointed out that these programs are mainly based on the findings of positive psychology and cognitive behavioural therapy, and Suissa (2008) voiced concerns about the lack of an underlying educational theory for these kinds of happiness classes. This article is intended to take one step in the direction of addressing and hopefully resolving this issue.

The idea of happiness (understood as eudaimonia) being the utmost goal of human beings is hardly new. Philosophers have discussed this topic, under various terms, throughout history. One of the most recent philosophical concepts has been conducted by Wilhelm Schmid (2000a) ${ }^{5}$ in his book Philosophie der Lebenskunst [Philosophy of the Art of Living]. Schmid created a theory about the good and beautiful life from a modern perspective under consideration of the philosophical history of this topic.

This article provides a critical comparative analysis of philosophical concepts of the art of living (with focus on Schmid's concept Lebenskunst) and positive psychological research from an educational point of view. It will explore the extent of common ground between these disciplines, where they differ, and where they might be complementary. It will also highlight aspects which are important for an educational approach to the art of living, the good life and teaching happiness in classrooms.

\section{Why Lebenskunst and Positive Psychology Today?}

There are some possible reasons for an increased interest in the question of the good life, the art of living and positive psychology today. Schmid (2000a, p. 9), for example, identifies a pattern throughout history, where uncertain times - especially uncertainty in regards to appropriate behaviour, values and norms - lead to uncertainty in life. This uncertainty triggers questions about how one should live, what purpose life has, what values one should have in life, and why one should act in accordance with certain values. The reason for an increased interest in these questions today, which also include the question of how to live a good life, can be found accordingly in the nature of the modern and postmodern age. Schmid identifies a degeneration of values and especially a loss of validation of these values and norms in (post-) modern societies. This loss of the validation of traditional norms and values came to pass through the deconstruction of religion and governmental authority, as well as the rapid globalisation and the change of our modern world, which increases the need for guidance and stability. The final argument ${ }^{6}$ for taking up the responsibility for one's own life and the desire to make it a beautiful one is more pressing today than ever. Through the loss of the belief in God and any form of afterlife, the notion of death can become much more powerful and fearsome for modern people.

Csikszentmihalyi's (2008, pp. 10-14) consideration about the actuality of the questions outlined above is based on a social assessment of life in postmodern America. In accordance with motivational theories, like Maslow's hierarchy of needs, he claims that some basic requirements need to be fulfilled for humans to become interested at all in questions about the good life. These basic needs are mostly of physiological and social origin: examples are food; sleep; shelter; company and belonging; as well as respect for and by others. Csikszentmihalyi points out that, when these problems are solved, people tend to start developing new desires which they believe are needed to be fulfilled for enjoying a good life. He observes that most of these upcoming needs are influenced by cultural beliefs, which today consists of money, cars, big TVs, expensive food, luxury holidays and the like. The problem he identifies with this behaviour is that human nature is able to accustom easily to new situations (a new car, good food) and subsequently new 
desires arise, which again are believed to be necessary for happiness and well-being in life. A spiral for the need to improve one's life, instead of taking pleasure and contentment of what one has, becomes apparent. Finally, people start to realise that this form of life does not provide the happiness and contentment they hoped to achieve in the first place, which is the point when people start to ask the question: "Is this all there is?" $(2008$, p. 13). One field, people can turn to, to answer this question is religion - either in the form of standard confessions, or of alternative beliefs of eastern origin or esoteric nature. Still, Csikszentmihalyi claims that today the existing religious systems can only provide a temporary solution (p. 14):

But religions are only temporarily successful attempts to cope with the lack of meaning in life; they are not permanent answers. At some moments in history, they have explained convincingly what was wrong with human existence and have given credible answers. From the fourth to the eighth century of our era Christianity spread throughout Europe, Islam arose in the Middle East, and Buddhism conquered Asia. For hundreds of years these religions provided satisfying goals for people to spend their lives pursuing. But today it is more difficult to accept their worldviews as definitive. The form in which religions have presented their truth - myths, revelations, holy texts - no longer compels belief in an era of scientific rationality, even though the substance of the truths may have remained unchanged. A vital new religion may one day arise again.

In this quote, Csikszentmihalyi indicates what he believes to be one of the main reasons why humanity in total was not able to improve their level of happiness and contentment despite all technical and social developments in the last centuries. He states that the truth about living a good life, which is "that the control of consciousness determines the quality of life" (2008, p. 20, italics added), can be traced back all the way through the existence of human records. The reasons for the limited progress, despite the existence of this knowledge over time, are those that "the kind of knowledge - or wisdom - one needs for emancipating consciousness is not cumulative. It cannot be condensed into a formula; it cannot be memorised and then routinely applied. [... It] must be earned through trial-anderror experience by each individual, generation after generation" (2008, p. 21). The second reason appears to be that the knowledge about how to control one's consciousness is dependent on the cultural context and needs to be adjusted and reformulated each time a cultural change occurs. The existing knowledge, although still valid, does not reach and correspond with today's people anymore.

Both Csikszentmihalyi and Schmid, although coming from different angles, reach the same conclusion that the cultural context plays a major role for the popularity of questions about the good life. This is not surprising as an increased general interest indicates a communal background for this development instead of factors on an individual basis. Still, the art of living has been a continuous topic of interest throughout time by individuals as well as cultural instances such as philosophy, religion and other spiritual belief systems. Another corresponding point of Schmid and Csikszentmihalyi is the notion of a possibly necessary change of culture. Csikszentmihalyi indicates in the quote above $(2008$, p. 14) that a "vital new religion may one day arise again"; Schmid (2000a, p. 103), on the other hand, proposes the development of a new or different modernity, which should preserve the freedom of postmodern societies but shift the focus from a fixation on pleasures in life to a more reflected way of living.

However, it is also important to point out the differences of the philosophical approach versus the psychological perspective. Overall, the psychological point of view seems to 
focus on the development of the individual and to emphasise strongly on enduring happiness as the utmost goal for a good and meaningful life. The philosophical concern seems to be more holistic in two regards: firstly, it focuses more on culture as a whole or even humankind in total - although Schmid's concept includes many references on an individual level as well; and, secondly, most art of living concepts do not state happiness and well-being as the only goal for a good life. On the contrary, even a life without happiness at all can still be regarded as a good life. The discrepancies of the interpretations of the good life will be discussed in more detail in the next section.

\section{Concept and Definition of a "Good" Life}

The term good life has a multitude of possible readings and interpretations in philosophy as well as in psychology and in every day language. Feldman (2004) identifies, for example, a morally, a beneficial, an aesthetic, a biological (good according to human nature) and an individual understanding of the term. Socrates' approach of a philosophical life, for example, is certainly based on a moral perspective, whereas the hedonistic and the psychological approach take a more individual and beneficially based angle. Schmid's concept of Lebenskunst seems to combine an individual view with certain aesthetic aspects.

To avoid misinterpretations, Schmid distinguishes between the good life and the beautiful life. The good life, for him $(2000 \mathrm{~b}, \mathrm{p} .19)$, is the expression for the popular modern and postmodern interpretation of living a life of pleasures and amenities. Similar to Csikszentmihalyi and Seligman, he sees such a life as the wrong path and as a life which is empty and dead. The beautiful life (2000b, p. 10), however, is marked by an active and conscious influence of the individual on his or her own life. It is the attempt to take responsibility for one's own life and shape it according to one's values, beliefs and imagination. This shaping of life is the aesthetic part of Schmid's concept of the art of living; for him, a beautiful life is what an individual defines as such for himself or herself. This approach ensures to not be limiting in terms of what a beautiful life might mean or how it can look like - the single defining factor is the mind and interpretation of the person living this life.

In contrast, Csikszentmihalyi and Seligman assume that enduring happiness is the utmost goal for human beings and, therefore, the purpose and definition of a good life. They emphasise enduring happiness to differentiate their concept from a pleasurable life, which would seek a maximisation of short-term pleasures instead of long lasting happiness. Enduring happiness is achieved through gratifications, which Seligman (2010, p. 112) regards to be the same as Aristotle's idea of eudaimonia. Although there are parallels especially in the definition of enjoyments (gratifications), which is in both cases the drawing of pleasure out of doing an activity for its own sake and not for the outcome of the activity - Aristotle's concept of eudaimonia seems to be a more abstract idea of an utmost goal which any human being strives to reach ${ }^{7}$. In an psychological context it is uncertain if we measure what happiness is or define happiness as what we can measure.

However compelling the idea of enduring happiness and well-being as overall goal for each individual might be, it cannot be assumed that a happy life is the same as the good life. Even when we assume that each individual is strongly motivated by a desire for lasting positive emotions in one's life, it seems to be a far stretch to employ gratifications in form of flow experiences as the silver bullet or only way to achieve this goal. Further, going back to the different interpretations of a good or beautiful life, in the end it is the 
value system and the beliefs a person has, which decide the outcome of one's normative judgement about one's own life. Somebody might believe, for example, that happiness and positive emotions are of evil nature and cannot be considered good at all; consequently, this person would not consider a life as a good one if it had many of these qualities. Someone else might have experienced many hardships in his or her life, which were never pleasant nor would reflect any kind of enjoyment through a state of flow. However, they might have shaped and developed the self and the character of this person in a way that he or she in the end could say, "I am content with who I am and how I evolved through this life - it was a good one." There are many different ideas and opinions about the nature of a good or beautiful life, which seems plausible, as every individual is, despite social and cultural influences and connections with the surrounding environment, unique ${ }^{8}$. Therefore, Schmid's more holistic approach to the topic and his individualistic definition of a beautiful life seems to be favourable. Nevertheless, due to the proximity of education and motivation, and for the sake of keeping a holistic perspective, it is important to keep in mind that striving for enduring happiness is a significant motivational factor for human beings.

\section{Concepts of the Self}

This section will show that the overlap between the philosophical and psychological notion of the self is rather limited, but that psychological research not only supports the idea of the existence of an entity inside each person, which can be identified as one's own self, but also contributes structural knowledge to this discourse. For an educational approach to the art of living, which is based on philosophical concepts that not only require the existence of a person's self but also depend strongly on its qualities, it deems important to analyse the meaning and scope of this term and how it is understood in the respective disciplines.

The self is an important term in Schmid's theory of the art of living as the care of the self, and, therefore, the shaping of one's own self, is the key element of a beautiful life. The philosophical discussion about the nature of the self, however, is highly conflictive and anything but unitary ${ }^{9}$. Schmid does not give a final definition himself, but he makes some anthropological assumptions, which he claims to be essential for his art of living concept, and names some qualities of the self as it is understood in his work. Schmid's (2000a, pp. 83-87) anthropological assumptions are that human nature is contradictory (e.g. one can love and hate with the same intensity); has a social component (one acts in relation to others, and power ${ }^{10}$ is an underlying principle); and has an ecological dimension, which means that the human being influences the environment, but one is also influenced by the environment. Further, human nature entails the dimension of choice, which implies that an individual can decide - more or less reflected - about oneself; the dimension of selfawareness (human beings are rational and able to identify connections); the dimension of care (in the meaning of prudent and forward-thinking behaviour); and the dimension of experiences, which implies that human beings are open for experiences, flexible for changes and able to draw conclusions because of their experiences. It is also necessary to mention that for Schmid the "human nature" is always a cultural one: humans (generally spoken) do not live alone but in groups and societies; therefore, the social and cultural aspect is essential for each being.

On the background of these anthropological assumptions, Schmid's notion of the self is a self-reflective and a self-shaping one. The subject or individual (hypokeimenon; subjectum - p. 239) is able to look beyond the immediate situation and circumstances, and 
contemplates one's own situation from an outside perspective. For Schmid, the self has a subject character and an object character; it contains an $I$, which is the actual, current instance talking or thinking about oneself, and a oneself, which is the reflective object part one is talking or thinking about. The I is also the artist, whereas the oneself is the object of the shaping process. Insofar, he states that one's self is the subject and its own object at the same time with a self-reflective and a self-forming relation ${ }^{11}$. What follows is that the I is shaping one's own self; therefore, one's I changes, which leads to a state of self-alienation. This alienation is followed by an orientation towards the other (new) self to come back to oneself. Schmid describes this process as a spiral one, as the individual is not turning towards the former self, but to the changed one. This spiral of self-shaping and selfannexation is the essential process of the art of living. It is favourable, as one has to be open for change instead of fearing the loss of identity, which often can have a limiting impact on people's self-development; the self preserves itself through continuous change. Therefore, change is an integrate part of Schmid's self-concept to form a beautiful self and a beautiful life. Implicitly Schmid solves the problem of protecting one's identity through pointing out that the state of self-alienation is not to be avoided, but in the context of the art of living even to be looked for. (2000a, pp. 239-242)

The self-concept in positive psychology, compared with Schmid's philosophical approach, is rather limited. One reason for this shortage might be that the focus on happiness as the ultimate goal does not necessarily need to take into account the shaping and transformation of the self; although, flow, as the single most potent technique to enduring happiness, entails personal growth. Another reason might be that the question of the self is traditionally a topic of personal psychology, social psychology and more recently neuropsychology, and therefore might not be considered necessary to be discussed in positive psychology in more depth. To provide a broader background for a dialogue between the disciplines about this topic I will outline briefly some more common aspects of self-concepts in the psychological discourse before summarising Csikszentmihalyi's adaptation for positive psychology.

The phenomenon of the self is a rather complicated matter and can be approached from various directions. One of the most recent developments in psychology is "a social brain sciences approach to understanding the self" (Heatherton et al., 2007). The objective is to identify the parts of the brain involved, when aspects of the self are active. According to Heatherton at al. (2007, p. 4), there is no one single location in our brain for the self and its functions (like thinking about one's own identity, personal traits and attributes, or recalling memories that are linked with one's self concept). These functions and memories are spread out through our brain and the combination of all these functions and memories form, what we perceive as our self. However, Heatherton et al. (2007, p. 5) also state that memories relevant for or connected with one's own self are stored differently than other memories: people are more capable of recalling memories connected with their own self than other memories; self-related memories are easier and quicker to recall than other memories $^{12}$.

Although the findings above underpin the phenomenon of the self itself, they do not explain the content and structure of one's self-concept. A recent psychological theory concerned with these questions is, for example, the self-complexity model discussed by McConnell \& Strain (2007). Interestingly they state that there is a relation between one's self-concept content and one's level of well-being; they claim that the "understanding of [this relation ...] is critical but far from complete" (2007, p. 52). The self-complexity model is an attempt to merge self-concept content (thoughts and opinions about oneself; 
compare Rogers' self-image) and self-concept structure (aspects like roles and relationships). An example would be the hypothetical person John (see figure 1), who might be a successful young student; he is on good terms with his family and quite extroverted when going out with his friends. Therefore, the self-concept he would draw for himself could contain different roles (aspects) like "family member", "student", "peer group"; and different content (attributes) like "helpful", "social", "outgoing", "intelligent" and "successful". John might attribute some of these contents with one role and some with more. In figure 1 we can see that he associates "social" with the family and the peer role; this attribute connects these two aspects of his self-concept, whereas the student aspect stands alone. McConnell \& Strain (2007, pp. 57-64) describe some phenomena regarding the self in connection with well-being, which can only be summed up at this point ${ }^{13}$. Firstly, there seems to be a negative correlation between the number of aspects (e.g. roles) and well-being: more aspects in one's self-concept have a dampening effect on one's wellbeing. An explanation for this might be an increasing level of stress and a diminished experience of control over the development of one's own self (p. 63). Secondly, McConnell \& Strain explain a concept they call "spill over" (p. 59), which describes the effect that a positive or negative impact on one of the attributes, which are connected to more than one aspect, influences the well-being of both aspects. If, for example, John receives negative feedback about him being social in a peer setting, this will also affect his self-image of the family aspect; therefore, both aspects will have a combined reducing impact on his self-esteem. If he receives positive feedback, accordingly it will have a combined positive effect. Feedback on not connecting attributes will only have a singular impact on the self-esteem. Thirdly, an individual with a more complex self-structure is less affected by the spill over effect, as feedback on special attributes impact only a smaller part of the self, whereas individuals with only one or two aspects are highly affected.

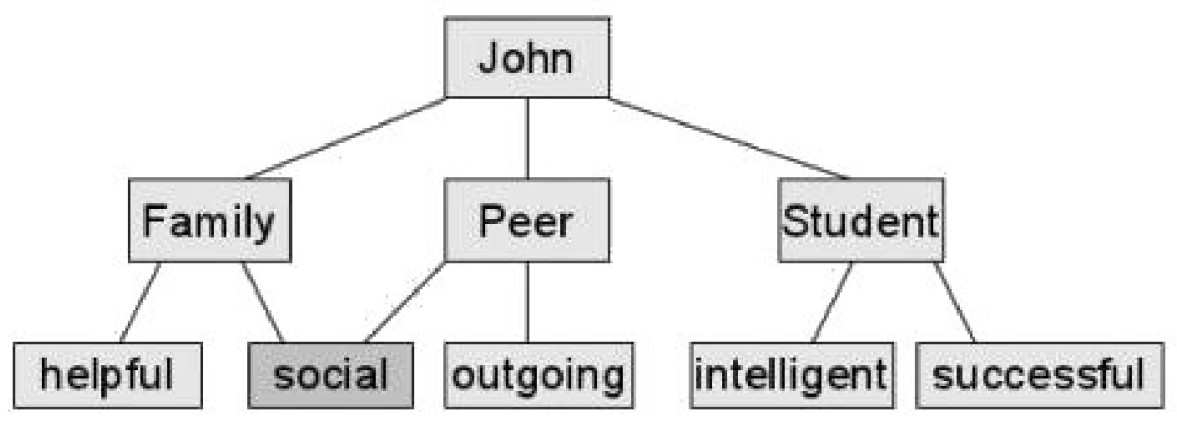

Figure 1: John's self-concept.

Csikszentmihalyi's notions about the self, at least in his book Flow (2008, p. 33-36), are quite superficial. He states that "the self is in many ways the most important element of consciousness, for it represents symbolically all of consciousness's other contents, as well as the pattern of their interrelations" (2008, p. 34). Therefore, the self is part of the consciousness and contains all content (memories, impressions, perception) that is part of the consciousness and the interrelations between these memories, impressions and perceptions. Further, he claims that the self foremost represents the "hierarchy of goals" (ibid.) we build up on the basis of our memories and experiences. According to 
Csikszentmihalyi, we are also only aware of a small part of our self at any given time: awareness of our body, or an idea, or a goal we try to achieve.

Comparing Schmid's philosophical contemplation of the self with the psychological approach shows that psychological research seems to focus on physiological and neurological aspects, as much as on the structure of the self-concept, including interactions of structural aspects and contents. The philosophical approach is mainly concerned with the contents - if one wants to use the psychological distinction in this context - or the quality of the self. Both are important research areas for understanding the self and its formation, but not all aspects are relevant for the contemplation at hand. Schmid's thoughts about the qualities of the self are more important for an educational approach to the art of living than structural or neurological considerations. However, we can learn from psychology that what one experiences as one's own self does have a representation in our brain - not a single area, but various functions and relevant stored memories. Further, memories are an important part of one's self-concept - especially memories that are encoded as relevant to the self. Therefore, educational processes (learning and experiences) can influence and support the formation of one's self, especially when the educational object (content, idea, skill) is found relevant to his or her own self by the pupil and linked with his or her self-concept. A conclusion one can draw here is that an educational art of living concept needs to pay attention to making the relevance of the lesson at hand for one's own self obvious and understandable for the student. After all, the shaping and growth of the self is the core concept of the art of living.

From a philosophical point of view, same as from a psychological one, there is so much more to say about the self, its formation and its implications. Perry (2002), for example, discusses questions about personal identity, memory, continuity of one's self over time and the formation and aspects of the self itself in depth. His contemplations expand into the structural domain of the self-concept and he partly reaches conclusions that are in line with psychological results. However, it is not possible to reflect on the whole discussion in the scope of this article; therefore, I refer the interested reader to Perry (2002), Sorabji (2006), Taylor (1989) and the literature mentioned above.

\section{Social Influences on Individual Human Beings}

A consideration of (post-)modern understandings of the human being as either an individual or a social being is quite significant for an art of living concept. Schmid's (2000a, pp. 73-75) approach defines the individual not only as the subject and the object of the art of living, but also as the single point of reference for a normative evaluation of one's own life. If one's own life is perceived as a good or beautiful one depends on the individual's norms and values alone, and not on the opinions of other people or on social conventions. The premise is, as discussed in the previous section, the existence of an entity in every individual, which is identified as his or her own self. This self is undoubtedly influenced by its surroundings and the social environment, but in the end it is capable of agreeing or disagreeing with social norms and conventions, and, hence, is able to form its own opinion. As one's own self and one's own life is the object that is formed in the art of living, and one's own self is also the forming entity - the artist - as a consequence one's own values and beliefs of the subject of the art of living form the basis for the evaluation and judgement of the formations outcome - one's own life. One reason for Schmid (2000b, pp. 9-10) to use the term "beautiful life" instead of "good life" is to emphasise the relevance of the individual's own beliefs, values and taste, and to avoid misunderstandings through varying interpretations of "good". However, the other (person) and the 
relationship between the subject of the art of living and the other are important factors in Schmid's (2000a, pp. 258-271) concept. The aspect of prudence and practical wisdom of the care of the self in the art of living requires the individual to take the other and his or her desires into account. This consideration is the foundation of Schmid's ethical concept for the art of living ${ }^{14}$. Schmid (ibid.) does not claim the human being to be an individual, distinct from society and social surroundings, but the opposite to be an individual with an inherent social component. A human being is a social one but also unique in his or her existence with an identifiable notion of self and, therefore, an individual.

The interrelations between the individual, the group and the cultural context seem somewhat different from a positive psychological point of view. According to Csikszentmihalyi, it is necessary for individuals "to overcome the anxieties and depressions of contemporary life, [... to] become independent of the social environment to the degree that they no longer respond exclusively in terms of its rewards and punishments" (2008, p. 16). In this notion, Csikszentmihalyi indicates a similar direction as Schmid does: the individual needs to be his or her own reference for what is desirable and how to live a good life. The underlying assumption for this claim, however, appears more drastic than Schmid's notion of the individual as a social being. Csikszentmihalyi requires the individual to provide his or her own rewards to reach the above indicated level of autonomy, which appears necessary for a happy life. But he also claims that it is more difficult to reach this autonomy as it might seem. The goal is to achieve control over one's own experiences, which "requires a drastic change in attitude about what is important and what is not" (ibid). The reason is that individuals in social contexts most often learn to postpone gratifications to an unspecified point in the future, which emphasises the importance of future outcome to be of higher value than the actual presence. Individuals in cultural settings learn early on that everything they are supposed to do - according to the cultural norms and demands - will be important for their own future and rewarded at a later point in time. Taken into account motivational comments like "You will need this when you want to get a job" or "This will help you become rich when you are grown up", which most will have heard in school or childhood at some point, make this claim empirically comprehensible. In addition, Csikszentmihalyi $(2008$, p. 17$)$ points out that cultures and social settings are dependent on this kind of reward system to keep the cultural subjects in line and the society alive.

The problems for the individual's good life and happiness, according to Csikszentmihalyi, are the suppression of the individual's desires (which are important to increase flow experiences and gratifications) and the fixation on future rewards (which sometimes is the promise of an upcoming "good life" itself) that prevent people in social settings from increasing their level of enduring happiness. Although I showed earlier that the "good life" is not necessarily a "happy life", the drive for happiness, especially enduring happiness, is a strong motivational factor for human beings in general, and, therefore, social control and reward settings limit the freedom of individuals and their options for having a good and beautiful life. This said, the answer cannot be to reject social affiliation and to retreat in hermitage - at least not on a general level. The difficulty is, as indicated earlier, to live as an autonomous member of a social group, mostly independent of the group's expectations and reward system.

Although cultural influences can have a huge limiting impact on the experience of flow for example through suppression, alienation or anomie (2008, pp. 85-86) - the immediate social setting, one's own family, can be quite beneficial for an individual's capacity to increase flow experiences. Csikszentmihalyi calls this the "autotelic family context" (2008, 
p. 89). This term describes a family setting, which is supportive for developing an autotelic personality. People with an autotelic personality "seem to enjoy situations that ordinary persons would find unbearable" (2008, p. 90), and, therefore, are more capable than other people of experiencing flow and enjoyments, despite their situation and the circumstances they are living in. The family context that supports the development of such an individual is marked by five traits: clarity in regards to rules, consequences and expectations; centreing on the here and now instead of focusing on future outcome of learning and behaviour; the possibility to choose from a variety of opportunities; commitment of the parents, which helps the child to develop trust; and challenges, provided by new and more complex opportunities through the parents (2008, pp. 88-89).

Some implications, following from these considerations, for an educational approach are that (i) educationalists have to be aware of the effect a future based educational approach can have on one's pupils. More desirable would be a setting and method of teaching that suggests the immediate relevance of the matter at hand for the pupils' life and their own self, and a way of educating (to avoid the term "teaching" here) that might even lead to repeated experiences of flow and enjoyments. (ii) Socialisation is always a part of education and, as stated above, necessary for human beings to live in a social context. The challenge is to allow a social education that enables the pupil to question his or her own cultural beliefs and values, and to become an autonomous individual, who is able to choose his or her place in and contribution to society based on prudence and practical wisdom. Terms like Bildung and critical thinking spring to mind in this context. (iii) Educational settings that support the development of an autotelic personality can help pupils to cope better with challenging situations in life and might enable them to experience more enjoyments despite their individual situations.

\section{Conclusion}

Considering the very different approaches positive psychology and the philosophy of the art of living take towards the nature of the human being and a definition of a good life, it is not surprising that the findings differ somewhat. However, reading between the lines and comparing terms and concepts, a great deal of concordance can be found between the disciplines. It might even be possible that both approaches show various aspects of the same phenomenon - eudaimonia. If this is the case, quantitative research results in (positive) psychology could support Aristotle's claim of this phenomenon being intercultural and consistent over time. This would confront some postmodern relativistic critique of holistic philosophical and anthropological approaches. Although the definition of what a good or beautiful life is differs in the concepts discussed above, it can be agreed upon that Schmid's concept subsumes the idea of a good life in the notion of being the maximisation of enduring happiness, as defined in positive psychology. Further, the drive for enduring happiness in life can be agreed on as a strong motivational factor for human beings in general, although the practical attempts to reach this goal are often ill considered and misleading. However, it is not unlikely that an individual engaged in the art of living experiences increasing amounts of flow due to shaping his or her own life according to his or her interests, through being strongly involved with every aspect of his or her own life, and through the subsequently following personal growth. Both Schmid and Csikszentmihalyi point out that in the end the individual him- or herself has to strive towards self-mastery (through the labour of care, respectively the control over consciousness). Although the human being is always a social one, the individual needs to 
become independent of society's punishment and reward systems to be able to develop an own art of living and a good life.

There are more aspects which need to be compared - like the control over consciousness versus the care of the self, or the question of meaning in life - but it seems already apparent that both approaches contribute to a more complex picture of the human being and its endeavour to live a good and beautiful life. Therefore, the dialogue in this article provides significant input for educational considerations and the development of an educational approach, as proposed elsewhere (Teschers, 2013).

\section{Notes}

'Search for 'happiness' (about 47,000 hits) combined with search for 'well-being' (about 573,000 hits) on www.amazon.com, 24.08.2011.

2

http://www.happyplanetindex.org

3

http://www.worldvaluessurvey.org

4

http://worlddatabaseofhappiness.eur.nl

5

For an English introduction to Schmid's philosophy see Teschers (2010).

6

For Schmid (2000a, p. 88) the finiteness of one's life and one's own death is the final argument for the individual to care for one's self and one's life.

7

If Aristotle's idea of eudaimonia has a representation in reality and whether it is the origin of all human action can be argued as well, but in any case, as enjoyments

experienced through flow can enhance the amount of "good" in a person's life they cannot be the same as eudaimonia, as Aristotle (1996, I,vii,8) points out that eudaimonia is a state of the utmost good and nothing can add to it.

8

Compare the philosophy of Hannah Arendt and Biesta (2006,p p. 82-89).

9

Perry (2002) wrote a strong philosophical argument about various aspects of this topic in his book Identity, Personal Identity, and the self. See also Charles Taylor's (1989) Sources of the self for an extensive discussion of the self and identity. Further, the book The Self? , edited by Galen Strawson's (2005), offers articles from various authors about a

phenomenal approach to the self.

10

Compare Foucault (1984).

11 Compare Kierkegaard's (2000, p. 351-352) notion of the self as “the relations's relating itself to itself"'.

12

Heatherton at al. refer, for example, to studies from Rogers (1977) and to Symons (1997).

13

For more detailed information and references to studies proving these statements refer to McConnell \& Strain (2007).

${ }^{14}$ See Schmid (2000a, pp. 60-71) or Teschers (2010, pp. 5-6) for more details about

Schmids ethical concept for an individual art of living approach. 


\section{References}

Aristotle (1996). The Nicomachean Ethics. London, England: Wordsworth Editions Limited.

Biesta, G. J. J. (2006). Beyond Learning: Democratic Education for a Human Future. Boulder, CO: Paradigm Publishers.

Csikszentmihalyi, M. (2008). Flow: The psychology of optimal experience. New York, NY: Harper Perennial.

Easton, M. (2006, May 22). The Politics of Happiness. BBC News, retrieved from http://news.bbc.co.uk.

Evans, J. (2008, February 18). Teaching happiness: the classes in wellbeing that are helping our children. Times Online, retrieved from http://www.thetimes.co.uk.

Feldman, F. (2004). Pleasure and the Good Life: concerning the nature, varieties and plausibility of hedonism. New York, NY: Clarendon.

Foucault, M. (1984). The Care of the Self, volume 3 of The History of Sexuality. London, England: Penguin Books.

Heatherton, T. F., Krendl, A. C., Macrae, C. N., \& Kelley, W. M. (2007). A Social Brain Sciences Approach to Understanding Self. In S. J. Sedikides, C. \& Spencer (Ed.), The Self chapter 1, (pp. 4-16). New York, NY: Psychology Press.

Kierkegaard, S. (2000). The Essential Kierkegaard. Princeton, NJ: Princeton University Press.

McConnell, A. R. \& Strain, L. M. (2007). Content and Structure of the Self-Concept. In C. Sedikides \& S. J. Spencer (Eds.), The Self. New York, NY: Psychology Press.

Perry, J. (2002). Identity, Personal Identity, and the Self. Indianapolis, IN: Hackett Publishing Company.

Rogers, T. B., Kuiper, N. A., \& Kirker, W. (1977). Self-reference and the encoding of personal information. Journal of Personality and Social Psychology, (35), 677-688.

Schmid, W. (2000a). Philosophie der Lebenskunst : Eine Grundlegung. Frankfurt, Germany: Suhrkamp.

Schmid, W. (2000b). Schönes Leben? : Eine Einführung in die Lebenskunst. Frankfurt, Germany: Suhrkamp.

Seligman, M. E. (2010). Authentic Happiness: using the new positive psychology to realise your potential for lasting fulfillment. London, England: Nicholas Brealey Publishing.

Sorabji, R. (2006). Self. Anciant and Modern Insights about Individuality, Life, and Death. Oxford, England: Oxford University Press.

Strawson, G., Ed. (2005). The Self? Oxford, England: Blackwell Publishing.

Suissa, J. (2008). Lessons from a new science? on teaching happiness in schools. Journal of Philosophy of Education, 42(3-4), 575-590.

Symons, C. S. \& Johnson, B. T. (1997). The self-reference effect in memory: A metaanalysis. Psychological Bulletin, (121), 371-394.

Taylor, C. (1989). Sources of the Self: The Making of the Modern Identity. Cambridge, MA: Harvard University Press.

Teschers, C. (2010). "Lebenskunst" - Schmid's Concept of the Art of Living. In PESA Conference Proceedings 2010 http://www.pesa.org.au/articles/2010-articles/PESA 2010 Article 02.pdf: Philosophy of Education Society of Australasia.

Teschers, C. (2013). An Educational Approach to the Art of Living. Knowledge Cultures, $1(2), 25-32$. 
van Suntum, U. \& Uhde, A. P. \&. N. (2010). Lebenszufriedenheit und Wohlbefinden in Deutschland: Studie zur Konstruktion eines Lebenszufriedenheitsindikators. Technical Report 259, DIW Berlin, The German Socio-Economic Panel (SOEP), http://ideas.repec.org/p/diw/diwsop/diw_sp259.html. 